\title{
Blockade of NGF-Induced Neurite Outgrowth by a Dominant- Negative Inhibitor of the Egr Family of Transcription Regulatory Factors
}

\author{
Yechiel Levkovitz, Kevin J. O'Donovan, and Jay M. Baraban \\ Departments of Neuroscience, Psychiatry, and Behavioral Sciences, Johns Hopkins University School of Medicine, \\ Baltimore, Maryland 21205
}

\begin{abstract}
Although it is well established that members of the Egr family of transcription regulatory factors are induced in many neuronal plasticity paradigms, it is still unclear what role, if any, they play in this process. Because NGF stimulation of pheochromocytoma 12 cells elicits a robust induction of Egr family members, we have investigated their role in mediating long-term effects elicited by NGF in these cells by using the Egr zinc finger DNA-binding domain as a selective antagonist of Egr familymediated transcription. We report that expression of this Egr inhibitor construct suppresses neurite outgrowth elicited by NGF but not by dibutyryl cAMP. To check that this Egr inhibitor
\end{abstract}

construct does not act by blocking the MEK/ERK pathway, which is known to mediate NGF-induced neurite outgrowth, we confirmed that the Egr inhibitor construct does not block NGF activation of Elk1-mediated transcription, a response that is dependent on this pathway. Conversely, inhibition of MEK does not impair Egr family-mediated transcription. Thus, we conclude (1) that induction of Egr family members and activation of the MEK/ERK pathway by NGF are mediated by separate signaling pathways and (2) that both are required to trigger neurite outgrowth induced by NGF.

Key words: NGF; PC12 cells; Egr1; zif268; MEK; ERK
The ability of neurotransmitters and neurotrophins to elicit rapid, robust changes in gene expression has generated considerable interest in the concept that this transcriptional response plays a key role in mediating long-term changes elicited by these agents (Sheng and Greenberg, 1990). The demonstration that late phases of neuronal plasticity are sensitive to nonselective inhibitors of macromolecular synthesis provided initial support for this hypothesis (Stanton and Sarvey, 1984; Montarolo et al., 1986; Frey et al., 1988; Abraham and Otani, 1991; Nguyen et al., 1994; Linden, 1996). Furthermore, the use of more selective approaches, such as strategies that block expression or activation of CRE-binding protein, an important regulator of immediate early gene expression, has provided compelling evidence in favor of this view (Dash et al., 1990; Guzowski and McGaugh, 1997; Lamprecht et al., 1997; Ahn et al., 1999).

Although there is now considerable support for the general concept that the immediate early gene response elicited by neuronal stimulation plays a central role in neuronal plasticity, much less is known about the role of individual genes induced in these plasticity paradigms. In previous studies, we and others have demonstrated that multiple members of the Egr family of transcription regulatory factors are robustly induced in a wide range of neuronal plasticity paradigms (for review, see O'Donovan et al., 1999). Although these findings suggest that Egr family members play a key role in mediating long-term changes underlying plasticity, this hypothesis has not been tested directly.

Received June 28, 2000; revised Oct. 13, 2000; accepted Oct. 13, 2000.

This work was supported by grants from the National Institute on Drug Abuse. We thank D. Ginty for helpful discussions and M. Greenberg, J. Milbrandt, D. Saffen, and S. J. Kim for providing plasmids.

Correspondence should be addressed to Dr. J. M. Baraban, Department of Neuroscience, Johns Hopkins University School of Medicine, 725 North Wolfe Street, Baltimore, MD 21205. E-mail: jbaraban@jhmi.edu.

Copyright (c) 2001 Society for Neuroscience $0270-6474 / 01 / 210045-08 \$ 15.00 / 0$
NGF stimulation of pheochromocytoma 12 (PC12) cells induces expression of two Egr family members, Egr1 (also called NGFI-A, zif268, or Krox24) and Egr4 (also called NGFI-C) (Milbrandt, 1987; Sukhatme et al., 1988; Crosby et al., 1991). Therefore, this in vitro paradigm, which has been studied extensively as a model of neuronal differentiation (Greene and Tischler, 1976), represents a convenient preparation for investigating the role of Egr family members in neuronal plasticity. In recent studies, Qu et al. (1998) demonstrated that overexpression of NAB2, a protein initially thought to function solely as a corepressor of Egr-mediated transcription (Svaren et al., 1996), blocks the ability of NGF to induce differentiation of PC12 cells. However, subsequent studies have revealed that NAB2 can either potentiate or inhibit the transcriptional activity of Egr family members depending on the promoter configuration of the specific target gene involved (Sevetson et al., 2000). Therefore, it is difficult to infer from that approach the role that Egr family members play in this plasticity paradigm. Furthermore, it is conceivable that NAB2 also exerts its cellular effects by modulating the activity of other transcription factors outside the Egr family. Because of these considerations, we sought to use an alternative strategy for suppressing Egr family-mediated transcription that would enable us to investigate the role of this transcription factor family in neuronal plasticity.

Because the four members of the Egr family share a highly conserved DNA-binding domain (Crosby et al., 1991; Gashler and Sukhatme, 1995; Swirnoff and Milbrandt, 1995), we reasoned that a truncated construct containing this domain would be useful as a dominant-negative inhibitor of transcription mediated by the Egr family. We have, in this study, used the PC12 cell preparation to evaluate whether this dominant-negative approach provides an effective means of blocking transcription driven by Egr family members. Furthermore, because characterization of the truncated construct confirmed that it is an effective and selective 
inhibitor of Egr family-mediated transcription, we also examined its effect on phenotypic changes induced by NGF in these cells.

\section{MATERIALS AND METHODS}

Reagents and plasmid constructs. The following reagents were obtained from commercial sources: NGF (Life Technologies, Gaithersburg, MD), dibutyryl-cAMP (db-cAMP; Sigma, St. Louis, MO), UO126 (Promega, Madison, WI), and DNA oligonucleotides containing the consensus binding sites for AP-1 and Sp1 (Santa Cruz Biotechnology, Santa Cruz, CA). UO126 was prepared in DMSO as a stock solution of $10 \mathrm{~mm}$. For studies with this drug, a comparable amount of DMSO was added to control wells.

To generate the $\Delta(1-249) \mathrm{Egr} 3$ insert by PCR, we used the forward primer 5'-CGG GGT ACC ATG CCG CTT ACT CTC AAG CCC ATC CGG, and the reverse primer 5'-CGC GGA TCC TCA GGC GCA GGT GGT GAC CAC AGG GGC, with the full-length rat Egr3 cDNA as template. The PCR product was digested with BamHI and EcoRI and ligated into the PCR3.1-Uni vector (Invitrogen, San Diego, CA). The insert was sequenced in its entirety to verify that no inadvertent mutations were introduced and that the proper reading frame was achieved.

Other plasmids used in this study have been described previously. A plasmid expressing a fusion protein composed of the GAL4 DNAbinding domain and the N-terminal segment of Egr3, GAL4/Egr3(1104), was prepared in our laboratory (O'Donovan et al., 2000). The cytomegalovirus-driven eukaryotic expression vector PCB6 containing the full-length Egr3 or Egr1 insert (Russo et al., 1995) and the luciferase reporter construct containing two Egr response elements (2XERE) (Crosby et al., 1991) were provided by J. Milbrandt (Washington University, St. Louis, MO). Reporter constructs based on segments of the TGF $\beta 1$ promoter (TG5, phTG7, and phTG7-4) were provided by S. J. Kim (National Institutes of Health, Bethesda, MD). A constitutively active MEK1 expression construct [MEK(DD)] was provided by $\mathrm{M}$. Greenberg (Harvard Medical School, Boston, MA). The Path Detect Elk Trans-Reporting System, which uses both the pFA2-Elk1 plasmid and Pfr-Luc, was purchased from Stratagene (La Jolla, CA). The pFA2-Elk1 plasmid encodes a fusion protein composed of the GAL4 DNA-binding domain and the $\mathrm{C}$-terminal activation domain of Elk1. A reporter construct driven by a segment of the rat Egr1 promoter containing four SRE sites, 4XSRE (Kumahara et al., 1999), was obtained from D. Saffen (University of Tokyo, Tokyo, Japan). The green fluorescent protein (GFP) expression plasmid was obtained from Clontech (Palo Alto, CA).

Cell culture. Human embryonic kidney 293 (HEK293) cells were maintained in 10 -cm-diameter dishes at $37^{\circ} \mathrm{C}$ in $5 \% \mathrm{CO}_{2}$ in DMEM supplemented with $10 \%$ fetal bovine serum, glutamine $(2 \mathrm{mM})$, and a penicillin-streptomycin mixture $(50 \mathrm{U} / \mathrm{ml})$. PC12 cells were maintained in medium containing DMEM, 10\% fetal calf serum, $5 \%$ horse serum, and $1 \%$ penicillin-streptomycin in an atmosphere of $5 \% \mathrm{CO}_{2}$ and at $37^{\circ} \mathrm{C}$.

Electrophoretic mobility shift assays. Gel-shift assays used to monitor binding of the truncated Egr3 construct to the ERE have been described previously (O'Donovan and Baraban, 1999). In brief, HEK293 cell extracts (15-20 $\mu \mathrm{g}$ of protein) were incubated with double-stranded oligonucleotides $\left(\sim 0.5 \mathrm{nM} ; 3-5 \times 10^{4} \mathrm{cpm}\right)$ containing the canonical ERE sequence, 5'-CTA GGA GCG GGG GCG CTC ATG-3' (bold letters indicate the ERE sequence), that had been end-labeled and purified. For competition studies with the unlabeled wild-type or mutant ERE (5'CTA GGA GCG GGT GCG CTC ATG-3'), these double-stranded oligonucleotides were preincubated with the cell extracts 15 min before adding the same concentration of labeled probe. Additional competition studies were performed with double-stranded oligonucleotides containing the consensus sequences of the AP- 1 or $\mathrm{Sp} 1$ response elements. The concentration of these oligonucleotides was 500-fold higher than that of the ERE probe.

Reporter assays. To monitor transcription mediated by the ERE or SRE, cells were cultured in six-well plates and transfected with one of the reporter plasmids $(1 \mu \mathrm{g} /$ well) using either the calcium phosphate method (HEK293 cells) (Chen and Okayama, 1987) or lipofectamine (PC12 cells; Life Technologies) along with expression plasmids as indicated $(0.1-1 \mu \mathrm{g})$ and either GFP $(0.4 \mu \mathrm{g})$ or $\beta$-galactosidase $(\beta$-gal; $50 \mathrm{ng})$ expression plasmids. Unless indicated otherwise, the $\Delta(1-249)$ Egr3 plasmid was used at $0.6-0.8 \mu \mathrm{g} /$ well, and "control" cells were transfected with the same amount of empty vector. For ERE reporter studies conducted in HEK293 cells, we used the 2XERE reporter construct used previously (O'Donovan and Baraban, 1999; O'Donovan et al., 2000). In pilot studies, we had difficulty detecting a robust response of this reporter to NGF stimulation of PC12 cells; therefore for ERE reporter studies conducted in these cells, we used the ERE reporter plasmid described by $\mathrm{Kim}$ et al. (1994). In examining whether TGF $\beta 1$ is a target gene regulated by the Egr family in PC12 cells, they demonstrated that NGF is able to stimulate expression of a reporter gene driven by the ERE contained in the TGF $\beta 1$ promoter. Accordingly, we used this reporter construct (TG5) for our PC12 cell studies. To insure that this response is mediated by the ERE, we confirmed that truncated segments of the promoter that retain or lack the ERE display the expected response to NGF or expression of Egr3. In reporter assays monitoring the response to NGF, cells were harvested $6-8 \mathrm{hr}$ after addition of NGF $(100 \mathrm{ng} / \mathrm{ml})$.

For the GAL4/Elk1 reporter assay, cells were transfected with both Pfr-Luc $(1 \mu \mathrm{g})$ and pFA2-Elk1 (50 ng). Luciferase activity was measured $2 \mathrm{~d}$ after transfection. Cells were rinsed twice with warm PBS, harvested in $1 \times$ reporter lysis buffer (Promega), and placed in $1.5 \mathrm{ml}$ tubes on ice. Extracts were vortexed for $10 \mathrm{sec}$ and centrifuged for $5 \mathrm{~min}$ at $14,000 \times$ $g$. Supernatants were collected, aliquoted, and used for both the luciferase (Promega) and luminescent $\beta$-gal (Clontech) assays, conducted according to the manufacturers' protocols. For each well, both luciferase and $\beta$-gal assays were performed in triplicate, and average values were used for further analysis. To help control for variability in transfection efficiency, $\beta$-gal activity or the number of GFP-positive cells was used to normalize the luciferase values obtained. In each reporter experiment, three or more sister wells were transfected with the constructs being assayed. All reporter assays were conducted in at least two independent experiments.

Neurite outgrowth assay. PC12 cells were plated on six-well plates precoated with poly-D-lysine at a confluence of 50-70\% $\left(\sim 1.0-1.5 \times 10^{5}\right.$ cells per $\mathrm{cm}^{2}$ ) and then cotransfected with the GFP plasmid and the expression plasmid being assayed at a stoichiometry of 1:5 to increase the likelihood that GFP-positive cells express the construct being evaluated. Based on GFP detection with standard fluorescence microscopy, transfection efficiency was in the range of $2-5 \%$. Neurite outgrowth was assessed 2-4 d after addition of NGF $(100 \mathrm{ng} / \mathrm{ml})$ or db-cAMP $(0.5 \mathrm{~mm})$. Processes longer than twice the diameter of the cell body were scored as neurites. To evaluate effects on neurite outgrowth, GFP-positive cells were scored in 10 fields from each of two wells. Morphological effects were evaluated in at least two independent experiments. To test the effect of MEK inhibition, cells were placed in serum-free media and then exposed to UO126 (15 $\mu \mathrm{M})$ or DMSO 30-40 min before addition of NGF.

\section{RESULTS}

\section{Characterization of the Egr inhibitor construct}

In previous studies, we found that Egr3 contains two independent transcriptional activation domains, referred to as $\mathrm{A} 1$ and $\mathrm{A} 2$ (Fig. $1 A)$, and that a truncated construct, $\Delta(1-214)$ Egr3, that is devoid of transcriptional activity retains its ability to bind to the ERE (O'Donovan et al., 2000). Accordingly, this or related constructs might be useful as inhibitors of Egr family-mediated transcription because they should block the ability of endogenously expressed Egr family members to bind to the ERE. In selecting a truncation site for generating an inhibitor construct of this type, we opted to delete the R1 domain, the binding site for NAB proteins that are able to modulate transcription by Egr family members (Russo et al., 1995; Svaren et al., 1996; Sevetson et al., 2000). Accordingly, we prepared the $\Delta(1-249)$ Egr3 construct that lacks both activation domains found in Egr3, as well as the R1 domain (Fig. 1 $A$ ).

Before testing whether this truncated construct is able to function as an inhibitor of ERE-mediated transcription, we first confirmed that it retains the ability to bind to the ERE. To do so, we expressed this truncated Egr3 construct in HEK293 cells and examined its ability to bind to a radiolabeled probe containing the consensus ERE sequence in a standard gel-shift assay (Fig. 1B). We found that the gel-shift complex formed by the truncated Egr3 construct is potently displaced by the unlabeled ERE, confirming that the inhibitor construct retains high affinity for the ERE sequence. In contrast, a mutant ERE, which contains a singlebase pair change that drastically reduces its affinity for Egr family members (Christy and Nathans, 1989a; Swirnoff and Milbrandt, 
A.

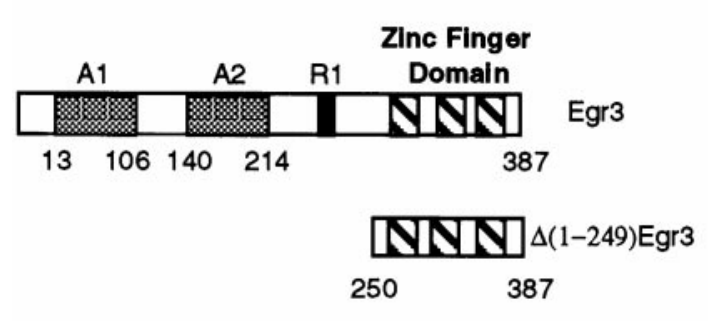

B.

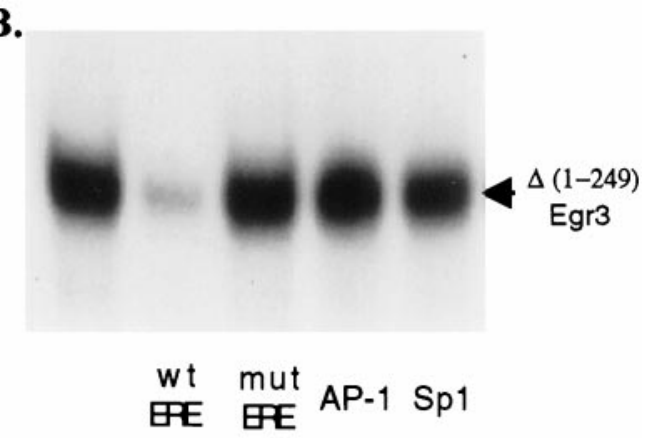

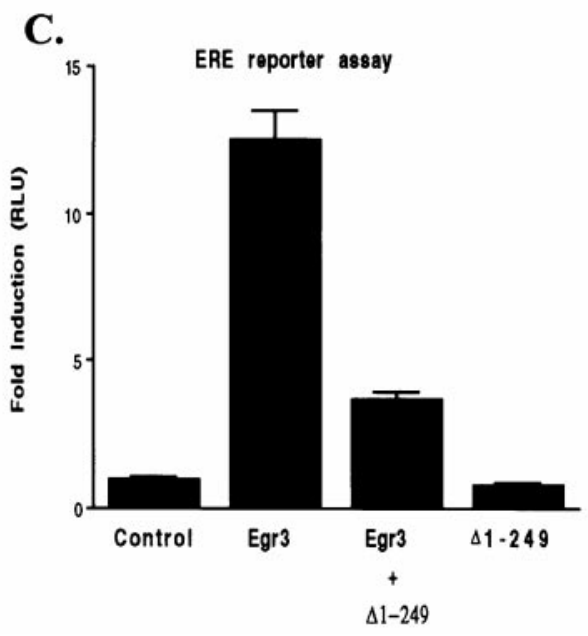

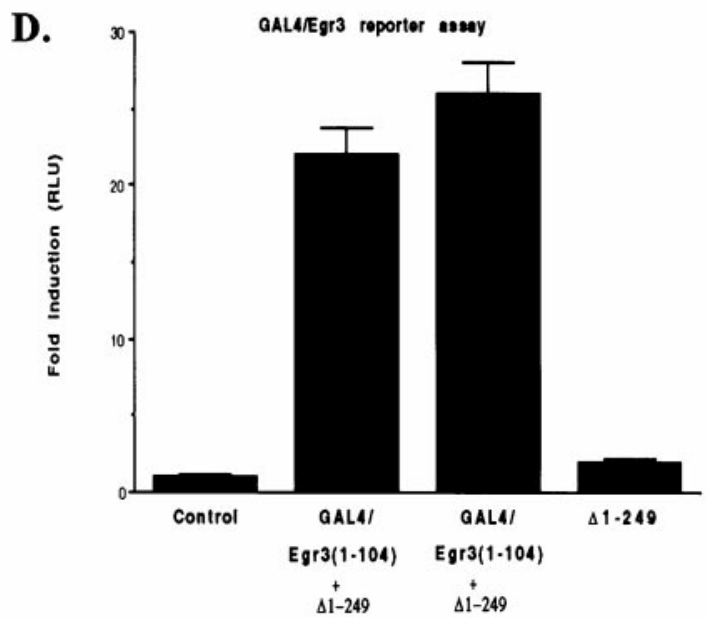

Figure 1. Characterization of the Egr inhibitor construct $\Delta(1-249)$ Egr3. A, Top, The bar shows a schematic diagram of Egr3 that contains three zinc finger motifs near its $\mathrm{C}$ terminal that mediate its interaction with the ERE, two distinct activation domains, A1 and A2, and a modulatory domain, R1, that serves as a binding site for NAB1 and NAB2. Bottom, The bar illustrates the Egr inhibitor construct $\Delta(1-249)$ Egr3 designed to retain the DNA-binding domain without the upstream activation or modulatory domains. $B$, The autoradiogram illustrates that the Egr inhibitor construct forms a gel-shift complex with the ERE oligonucleotide probe. Formation of this complex is blocked by addition of unlabeled ERE [wild-type ERE (wt ERE)] but not a mutant ERE (mut ERE) in which a single base pair has been changed. (Wild-type and mutant ERE oligonucleotide sequences are provided in Materials and Methods.) Unlabeled ERE oligonucleotides were added at the same concentration as the ERE probe ( $\sim 0.5 \mathrm{nM})$. In addition, neither AP-1 nor Sp1 oligonucleotides inhibit binding of the Egr inhibitor construct to the ERE, when added at 500-fold higher concentration than the ERE probe. $C$, HEK293 cells were transfected with a luciferase reporter plasmid containing a tandem repeat of ERE sites in its promoter as well as with the other expression plasmids listed under each column of the bar graph [Egr3 plasmid, $0.5 \mu \mathrm{g} / \mathrm{well} ; \Delta(1-249)$ Egr3, $0.5 \mu \mathrm{g} / \mathrm{well}]$. The ability of Egr3 to increase luciferase activity in extracts from these cells was blocked by the Egr inhibitor construct. As expected, the Egr inhibitor construct was unable to increase luciferase activity compared with that in control cells that only received the ERE luciferase reporter plasmid. $D$, HEK293 cells were transfected with a luciferase reporter plasmid containing a tandem repeat of GAL4 response elements in its promoter as well as with the other expression plasmids listed under each column. GAL4/Egr3(1-104) refers to a chimeric protein generated by fusing the GAL4 DNA-binding domain with the A1 activation domain of Egr3. In contrast to its ability to block stimulation of reporter gene expression by full-length Egr3, the Egr inhibitor construct [ $\Delta(1-249)$ Egr3; $0.5 \mu \mathrm{g} /$ well] does not block the increase in luciferase activity driven by the GAL4/Egr3(1-104) construct (0.5 $\mu \mathrm{g} /$ well) acting on a GAL4 reporter plasmid. In $C$ and $D$ and the figures that follow, " $\Delta 1-249$ " refers to $\Delta(1-249)$ Egr3. Error bars shown in this and subsequent figures represent the SEM. Data shown in $C$ and $D$ are presented in relative luciferase units $(R L U)$.

1995; O’Donovan et al., 1999), does not inhibit formation of the gel-shift complex. As a further check on the specificity of the truncated construct, we also confirmed that its gel-shift complex is not displaced by double-stranded oligonucleotides containing AP-1 or Sp1 consensus sequences even when used at concentrations 500-fold higher than the ERE probe (Fig. 1B).

Having demonstrated that the truncated construct $\Delta(1-$ 249)Egr3 is able to bind to the ERE consensus sequence with high affinity and specificity, we next examined its ability to inhibit transcription driven by full-length Egr family members by the use of a conventional, luciferase-based ERE reporter assay. We found that the truncated construct strongly suppresses the ability of Egr3 to stimulate expression of the luciferase reporter (Fig. 1C). Furthermore, as expected, the truncated construct is devoid of transcriptional activity in this assay. To check that the inhibition displayed by the truncated construct does not merely reflect nonspecific suppression of transcription, we assessed the effect of the $\Delta(1-249)$ Egr3 on transcription driven by a GAL4 fusion protein, in which the GAL4 DNA-binding domain has been fused to one of the activation domains of Egr3, GAL4/Egr3(1-104) (O'Donovan et al., 2000). As expected from the specificity displayed in the gel-shift assays, the truncated construct did not impair the activity of the GAL4/Egr3(1-104) fusion protein in this assay (Fig. 1D). Thus, this initial characterization of the truncated Egr3 construct confirmed that it possesses the ability to block transcription mediated by Egr family members selectively.

\section{Egr inhibitor construct blocks NGF activation of ERE- mediated gene expression}

Because we wanted to use the Egr inhibitor construct $\Delta(1-$ 249)Egr3 in PC12 cells to investigate the role of the Egr family in mediating long-term changes elicited by NGF, we used similar 
Figure 2. The Egr inhibitor construct selectively blocks ERE-mediated transcription in PC12 cells. $A, \mathrm{PC} 12$ cells were transfected with a luciferase reporter plasmid (TG5) that is driven by a segment of the TGF $\beta 1$ promoter containing an ERE site. As found in HEK293 cells, the Egr inhibitor construct blocks the increase in luciferase activity induced by Egr3. B, The Egr inhibitor construct does not block the increase in luciferase activity displayed by cells transfected with the GAL4/Egr3(1-104) expression construct and the GAL4 reporter plasmid. $C$, In PC12 cells transfected with the ERE reporter, NGF induces a strong increase in luciferase activity that is suppressed by the Egr inhibitor construct. Cells were harvested $6 \mathrm{hr}$ after addition of NGF. D, PC12 cells were cotransfected with a GAL4 reporter plasmid and an expression plasmid encoding a chimeric protein generated by fusing the GAL4 DNA-binding domain with the C-terminal activation domain of Elk1 (Path Detect Elk Trans-Reporting System, Stratagene). Stimulation of these cells with NGF (6 hr) triggers a robust increase in luciferase activity that is not blocked by cotransfection with a third plasmid encoding the Egr inhibitor construct.
A.

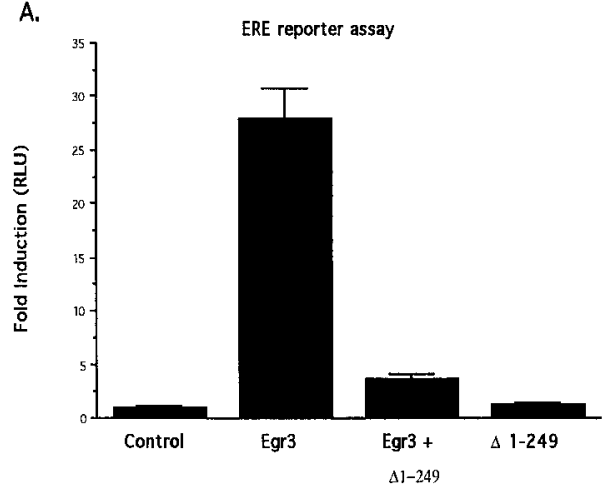

C.

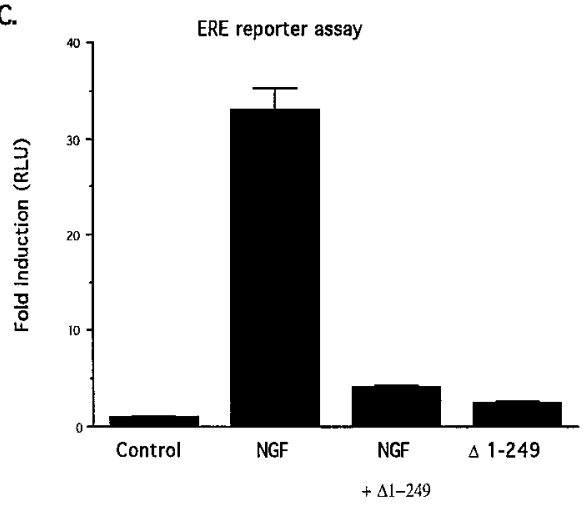

B.

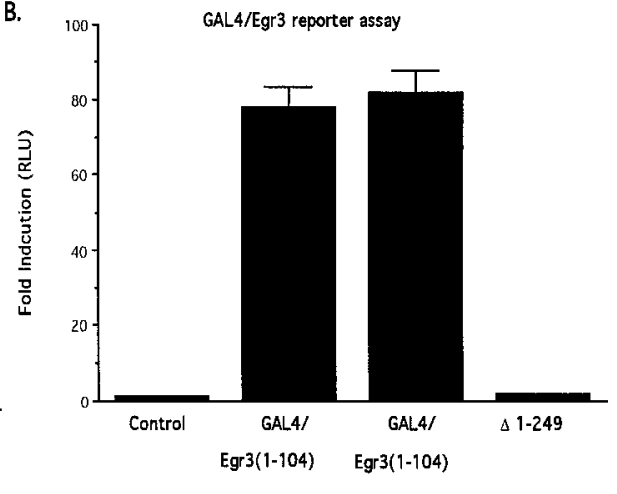

D.

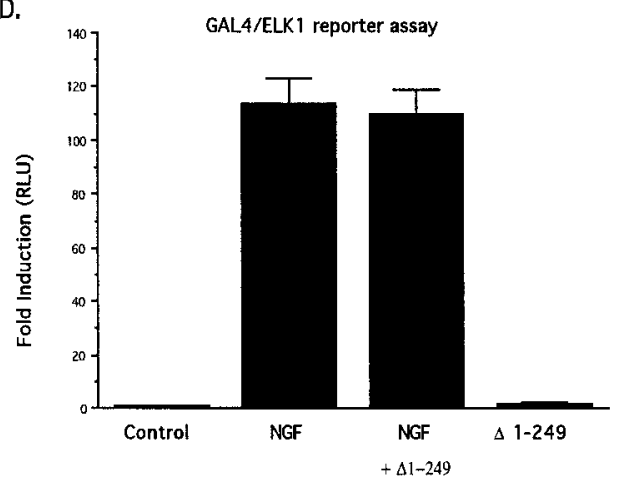

approaches to check its efficacy and specificity in these cells. In particular, we wanted to assess whether the inhibitor construct is able to block the ability of endogenous Egr family members, induced by NGF, to stimulate transcription. As expected, we found that $\Delta(1-249)$ Egr3 markedly suppressed the ability of Egr3 to stimulate the ERE reporter (Fig. $2 A$ ) but did not affect the activity of a GAL4 reporter construct that was stimulated by cotransfection with the GAL4/Egr3(1-104) construct described above (Fig. 2B). Furthermore, the Egr inhibitor construct markedly reduced the ability of NGF to stimulate ERE-mediated transcription, demonstrating that it is also highly effective at blocking the activity of endogenously expressed Egr family members (Fig. 2C).

Because it is conceivable that blockade of this response to NGF could be caused by unintended interference by the inhibitor construct with NGF receptor activation or expression, we also monitored the effect of the Egr inhibitor construct on the ability of NGF to stimulate the transcriptional response mediated by the C-terminal activation domain of Elk1, a ternary complex factor that binds with the serum response factor (SRF) to the SRE (Gille et al., 1992; Marais et al., 1993; Price et al., 1996; Johnson et al., 1997). In this assay, a fusion protein composed of the GAL4 DNA-binding domain fused to the C-terminal activation domain of Elk1 is used to drive expression of a luciferase reporter gene under the control of a GAL4 response element. In contrast to its marked suppression of the ability of NGF to stimulate the ERE reporter, the Egr inhibitor construct did not affect NGF's activation of the GAL4/Elk1 reporter, indicating that the Egr inhibitor construct does not produce a nonspecific blockade of NGF receptor activation (Fig. 2D).

These initial studies characterizing the selectivity of the Egr inhibitor construct demonstrate that it blocks transcription medi- ated by the ERE but not by the GAL4 response element. To provide additional assurance that the Egr inhibitor construct selectively blocks ERE-mediated transcription, we also checked its effect on transcription mediated by another response element, the SRE. To this end, we used a reporter driven by a fragment of the Egr1 promoter that contains multiple SREs (Christy and Nathans, 1989b; Kumahara et al., 1999). NGF stimulation of this reporter was not blocked by the Egr inhibitor construct $\Delta(1-$ 249)Egr3, providing further evidence that it selectively inhibits ERE-mediated transcription (Fig. 3).

\section{Egr inhibitor construct suppresses NGF-induced neurite outgrowth in PC12 cells}

Because we found that the Egr inhibitor construct was able to block the ability of NGF to stimulate ERE-mediated transcription in PC12 cells, we examined its effect on NGF-induced neurite outgrowth in these cells. For these studies, cells were transfected with a GFP expression plasmid and either the inhibitor construct or the same expression plasmid without an insert. The inhibitor construct produced a marked reduction in the percentage of GFP-positive cells having one or more neurites when examined $2 \mathrm{~d}$ after initiation of NGF treatment (Figs. 4, 5A). When cells were examined after 72 or $96 \mathrm{hr}$ of NGF treatment, we obtained similar results; only $27 \pm 4 \%$ (mean \pm SEM) or $33 \pm 6 \%$ of GFP-positive cells, respectively, scored as neurite bearing.

To check whether the inhibitory effect on neurite outgrowth produced by the Egr inhibitor construct might be caused by interference with neurite outgrowth per se rather than by the intended blockade of ERE-mediated transcription, we also examined the effect of the Egr inhibitor construct on neurite outgrowth induced by db-cAMP (Gunning et al., 1981a,b). In contrast to NGF that elicits slow development of stable neurites, db-cAMP 


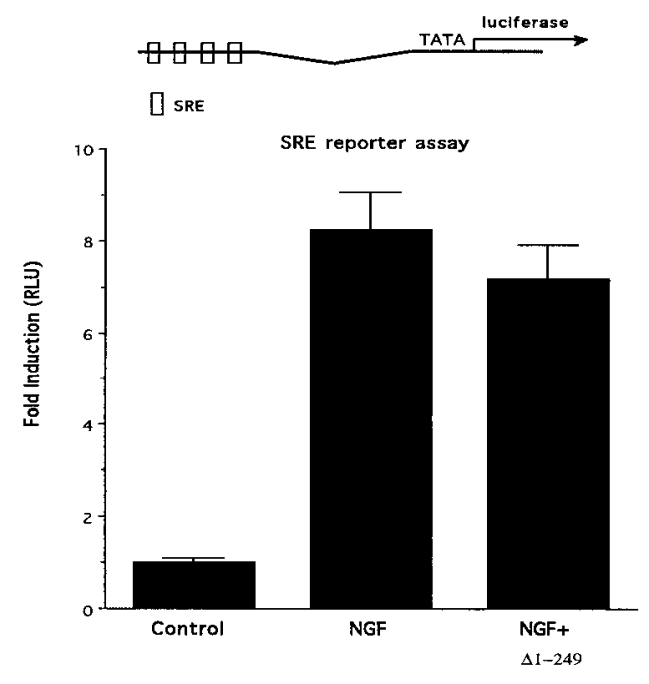

Figure 3. Selectivity of the Egr inhibitor construct. Top, PC12 cells were transfected with a luciferase reporter plasmid driven by a segment of the Egr1 promoter that contains four SRE sites. Bottom, NGF treatment increases luciferase activity in extracts prepared from these cells. This increase is not blocked by cotransfection with the Egr inhibitor construct.

\section{Control}
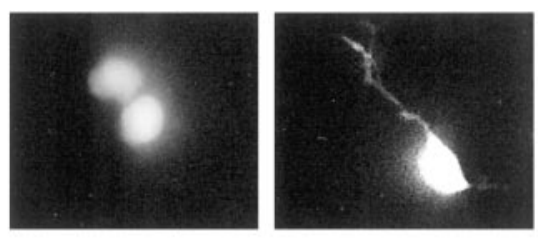

NGF

$\Delta 1-249$
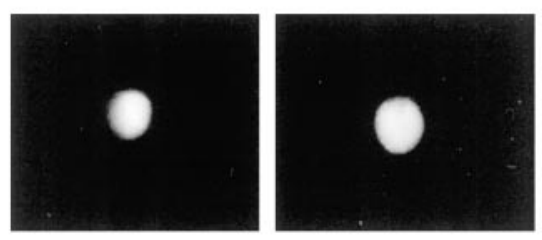

NGF

$\stackrel{+}{\Delta 1-249}$

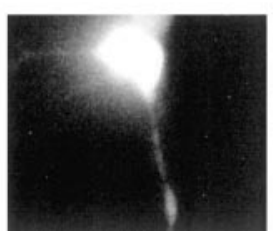

A.

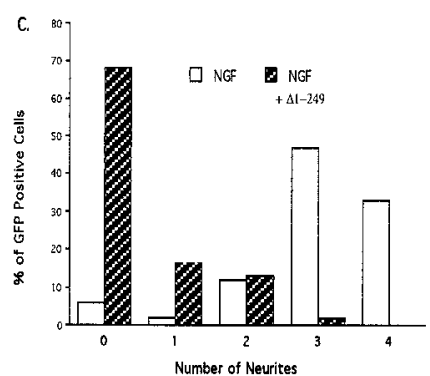

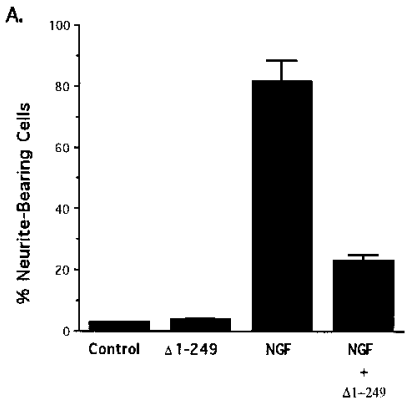

B.

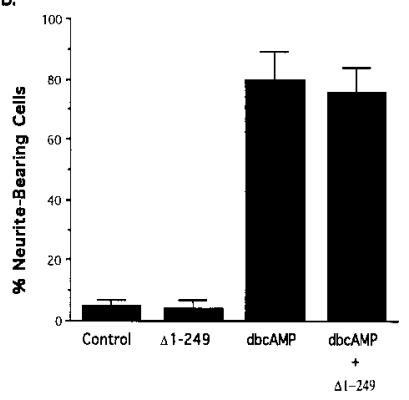

D.

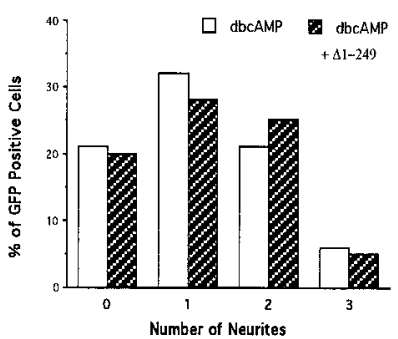

Figure 5. Quantitative analysis of effects of the Egr inhibitor construct on neurite outgrowth. $A, \mathrm{PC} 12$ cells expressing GFP were scored as either neurite bearing or not. Exposure to NGF elicits neurite outgrowth in $\sim 80 \%$ of cells, indicating that expression of the GFP construct does not alter this response to NGF. Cotransfection with the Egr inhibitor construct markedly reduced the percentage of neurite-bearing cells observed after NGF treatment $(N G F+\Delta 1-249)$. $B$, The Egr inhibitor construct does not reduce the percentage of neurite-bearing cells induced by exposure to db-cAMP $(d b c A M P+\Delta 1-249)$. $C$, GFP-positive cells were grouped according to the number of neurites present after NGF treatment. Cotransfection with the Egr inhibitor construct produces a marked shift toward lower neurite number. $D$, The Egr inhibitor construct does not affect the distribution of neurite number after db-cAMP treatment. Values shown in $C$ differ slightly from those in $A$ because they are based on independent counts. Data presented in this figure are from cells counted $2 \mathrm{~d}$ after NGF or db-cAMP treatment. Over 500 cells were scored for each experimental condition.
dbcAMP $\stackrel{+}{+}-249$
Figure 4. The Egr inhibitor construct selectively blocks neurite outgrowth induced by NGF. PC12 cells were transfected with a GFP expression plasmid with or without $\Delta(1-249)$ Egr3, and cell morphology was monitored by fluorescence microscopy. Top, The typical small, round, and flat morphology found in undifferentiated PC12 cells (left; control) is shown. After treatment with NGF (right), cells elaborate one or more neurites. Middle, The Egr inhibitor construct, which does not induce neurite outgrowth (left), blocks neurite outgrowth triggered by NGF [right; NGF $+\Delta(1-249)$ Egr3]. Bottom, Neurite outgrowth can also be induced by db-cAMP (left) that is not affected by cotransfection with the Egr inhibitor construct [right; db-cAMP $+\Delta(1-249)$ Egr3]. Images shown were obtained $2 \mathrm{~d}$ after addition of NGF or db-cAMP.

triggers a more rapid, transient form of neurite outgrowth that is independent of RNA synthesis. As expected, the Egr inhibitor construct did not impair the ability of db-cAMP to induce neurite outgrowth (Figs. 4, 5B).

Although NGF still induced neurite outgrowth in approximately one-fourth of GFP-positive cells that were cotransfected with the $\Delta(1-249)$ Egr3 construct, careful inspection of this pop- ulation of cells indicated that they elaborated fewer neurites. Thus, the Egr inhibitor construct appeared to be exerting an effect on this population of cells even though they were still scored as neurite bearing. To test this impression, we conducted a quantitative analysis of the effect of the Egr inhibitor construct on the distribution of neurite number among cells exposed to NGF or db-cAMP. This analysis confirmed that the Egr inhibitor construct reduces the number of neurites among the minority of NGF-treated cells scored as neurite positive (Fig. 5C). In contrast, the Egr inhibitor construct did not affect the distribution of neurite number after db-cAMP stimulation (Fig. 5D).

If the ability of the Egr inhibitor to block NGF-induced neurite outgrowth were caused by its ability to block ERE-mediated transcription, then one would predict that both of these effects of the inhibitor would display similar concentration-response profiles. To test this prediction, we examined the effect of varying the amount of the Egr inhibitor plasmid used for transfection on both of these parameters. Although we found that they display similar response profiles, the ERE reporter assay was more sensitive than was the neurite outgrowth assay to the Egr inhibitor (Fig. 6), suggesting that nearly complete inhibition of ERE-mediated transcription is required to inhibit neurite outgrowth. 

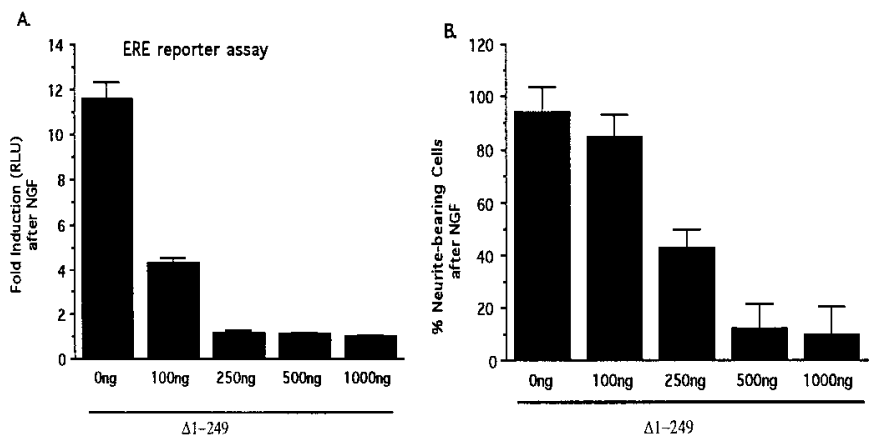

Figure 6. Parallel effects of the Egr inhibitor construct in blocking neurite outgrowth and ERE-mediated transcription by NGF. $A$, The amount of Egr inhibitor plasmid used for transfection was varied from 0 to $1000 \mathrm{ng} /$ well. To keep the total amount of transfected DNA constant, we added appropriate amounts of pCB6 plasmid. The bar graph presents the increase in luciferase activity detected in cell extracts harvested 6-8 hr after treatment with NGF. $B$, The effect of varying the amount of Egr inhibitor plasmid on the percentage of cells scored as neurite bearing after NGF exposure is presented in this bar graph. In the absence of NGF, $9 \pm 6 \%$ (mean \pm SEM) of cells were scored as bearing neurites.

\section{Egr inhibitor and MEK blockade suppress neurite outgrowth by acting on distinct signaling pathways}

Because MEK activation plays a central role in mediating NGFinduced neurite outgrowth (Cowley et al., 1994) and the MEKsignaling pathway has been implicated in activating immediate early gene expression (Segal and Greenberg, 1996), we tested whether NGF induction of Egr family members is mediated by MEK. If this were the case, then blockade of MEK activation might suppress neurite outgrowth, in part, because it blocks induction of Egr family members by NGF. To test this model (Fig. $7 A$ ), we examined whether MEK inhibition, which blocks NGFinduced neurite outgrowth in PC12 cells (Pang et al., 1995), blocks the ability of NGF to stimulate ERE-mediated transcription. As expected, we found that UO126 (15 $\mu \mathrm{M})$, a selective MEK inhibitor (Favata et al., 1998), suppressed NGF-induced neurite outgrowth (Fig. 7B). However, this drug did not diminish the ability of NGF to stimulate the ERE reporter (Fig. $7 C$ ). To study an additional positive control on the efficacy of this compound to inhibit the MEK-ERK pathway in these experiments, we confirmed that UO126 abolished the ability of NGF to stimulate the Elk1 reporter (Fig. $7 C$ ), a response mediated by the MEK-ERK pathway (Segal and Greenberg, 1996; Johnson et al., 1997). Taken together, these experiments indicate that the ability of NGF to stimulate ERE-mediated transcription is insensitive to MEK inhibition. Accordingly, these findings indicate that NGF is able to induce Egr family member expression via an MEKindependent pathway.

Because MEK activation is sufficient to induce neurite outgrowth, we wanted to know whether Egr-mediated transcription is also involved in this process. To assess this possibility, we first checked whether a constitutively active MEK construct (Cowley et al., 1994) stimulates the activity of the ERE reporter and found this to be the case (Fig. $8 A$ ). As expected, this increase is blocked by the Egr inhibitor construct. Furthermore, the ability of MEK to trigger neurite outgrowth is also inhibited by the Egr inhibitor construct (Fig. 8B). Thus, neurite outgrowth triggered by either NGF or activated MEK is dependent on ERE-mediated transcription (Fig. 8C). However, induction of Egr family members alone does not appear to be sufficient to trigger neurite outgrowth, because transfection of PC12 cells with an Egr1 expres-
A.

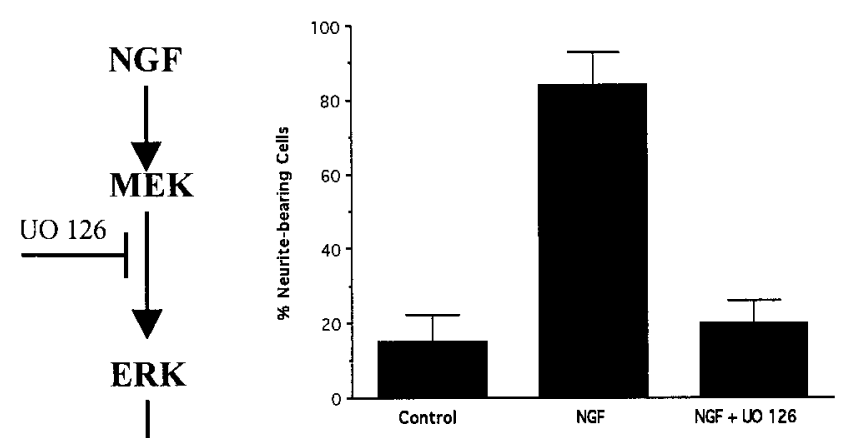

C.

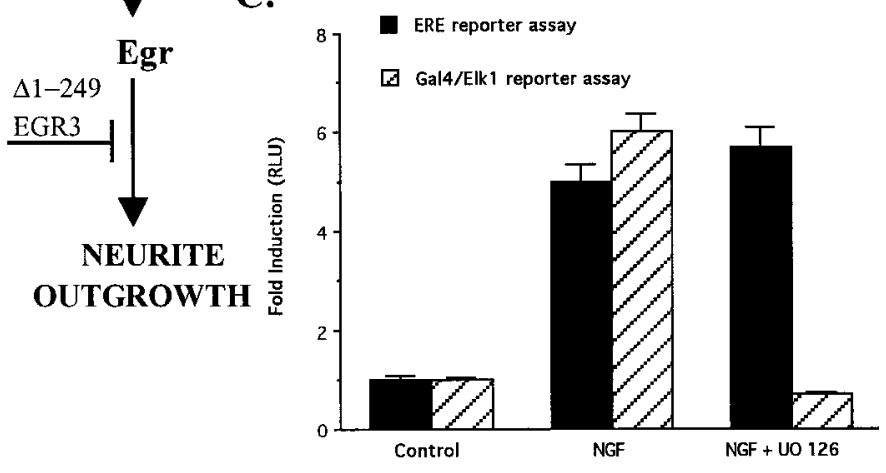

Figure 7. Effect of MEK inhibition on neurite outgrowth and transcriptional responses stimulated by NGF. $A$, This schematic diagram depicts a scenario in which Egr induction is located downstream of MEK activation by NGF. In this model, UO126, an MEK inhibitor, and the Egr inhibitor construct $\Delta(1-249)$ Egr3 block at sequential steps in the signaling pathway linking NGF receptor activation to neurite outgrowth. $B$, The bar graph presents the effect of pretreating cells with UO126 $(15 \mu \mathrm{M})$ on neurite outgrowth induced by NGF. $C$, The bar graph shows the effect of UO126 $(15 \mu \mathrm{M})$ on the ability of NGF to stimulate ERE-mediated and Elk1mediated transcription.

sion vector did not significantly increase the percentage of cells displaying neurite outgrowth (control, $10 \pm 3 \%$, vs Egr1, $14 \pm$ $5 \%$; mean $\pm \mathrm{SEM}$ ).

\section{DISCUSSION}

The two major goals of this study were (1) to determine whether the highly conserved DNA-binding domain shared by Egr family members could be used as an inhibitor of ERE-mediated transcription and, if so, (2) to use this Egr inhibitor construct to investigate the role of Egr family members in mediating the effects of NGF on PC12 cells. Initial characterization of this putative inhibitor construct, $\Delta$ (1-249)Egr3, in HEK293 and PC12 cells confirmed its inhibitory properties. Biochemical studies demonstrated that the truncated protein binds to the ERE with high affinity and selectivity; functional studies established that this truncated construct selectively blocks expression of a reporter gene under the control of the ERE. On the basis of these encouraging results, we proceeded to examine the effect of this Egr inhibitor construct on the response of PC12 cells to NGF and found that it caused a marked decrease in neurite outgrowth. Thus, this set of experiments indicates that the Egr family of transcription factors plays a key role in mediating the long-term phenotypic changes induced by NGF in these cells.

This inference is supported by several additional control experiments aimed at excluding the possibility that suppression of 

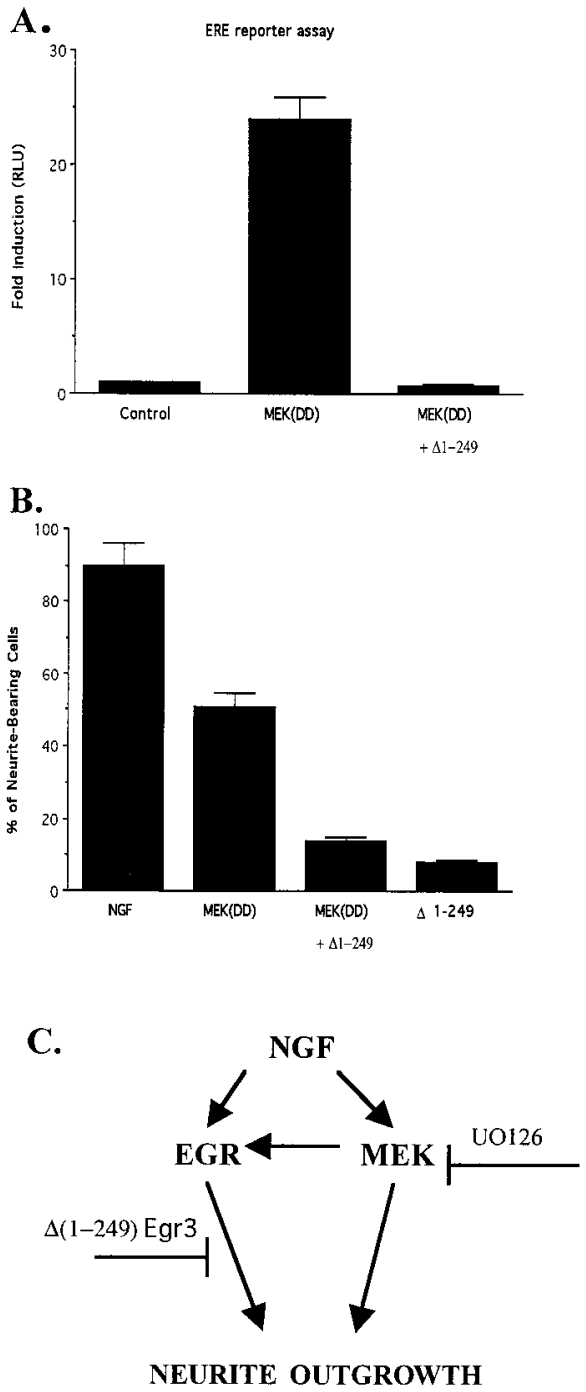

Figure 8. MEK stimulation of ERE-mediated transcription: role in neurite outgrowth. $A$, The ERE reporter plasmid was used to monitor the effects of a constitutively active MEK1 construct [MEK(DD); $0.5 \mu \mathrm{g} /$ well] on EREmediated transcription in PC12 cells. Cotransfection with the activated MEK construct increased luciferase activity in extracts from these cells. This increase is abolished when the MEK construct is cotransfected with the Egr inhibitor construct. $B$, Transfection with the MEK(DD) expression plasmid elicits neurite outgrowth that is blocked by cotransfection with the Egr inhibitor construct. $C$, The schematic diagram presents a model of signaling pathways mediating NGF-induced neurite outgrowth that incorporates the results presented in this report. A key feature of this model is that separate signaling pathways link NGF receptor stimulation to induction of Egr family members and activation of MEK. This inference is based on our finding that NGF stimulation of ERE-mediated transcription is not blocked by inhibition of MEK. These findings suggest that both of these responses to NGF are required for NGF to trigger neurite outgrowth, because blockade of either pathway suppresses the ability of NGF to elicit neurite outgrowth. However, at first glance, the assertion that both MEK activation and Egr family induction are required for neurite outgrowth appears to be at odds with the observation that constitutively activated MEK is sufficient to induce neurite outgrowth. This ostensible discrepancy is explained by our observation that the constitutively active MEK construct stimulates ERE-mediated transcription, allowing it to comply with both requirements for neurite outgrowth stipulated by this model. Further confirmation of this scenario is provided by the ability of the Egr inhibitor construct to block neurite outgrowth induced by the constitutively active MEK construct. However, it appears that induction of Egr family members is not sufficient to induce neurite outgrowth because transfection of these cells with Egr1 does not trigger neurite outgrowth. Therefore, the model shown includes a second arrow emanating from MEK leading to neurite outgrowth.
NGF-induced neurite outgrowth might be caused by unintended effects of this construct rather than by its ability to block EREmediated gene expression. First, its inhibitory effects on NGFinduced neurite outgrowth cannot be attributed to global suppression of NGF signaling or macromolecular synthesis because it did not suppress the ability of NGF to stimulate other reporter constructs. Second, because NGF activation of the Elk1 reporter is mediated by the MEK-ERK pathway, the inability of the Egr inhibitor construct to suppress this response to NGF also implies that its blockade of neurite outgrowth is not caused by inhibition of the MEK-ERK pathway. Third, the ability of db-cAMP to induce neurite outgrowth is unimpaired by the Egr inhibitor construct, indicating that it does not interfere with neurite outgrowth per se. Last, comparison of the concentration-response profiles for blockade of neurite outgrowth and the ERE reporter assay confirmed that they are similar, bolstering the conclusion that the observed blockade of NGF-induced neurite outgrowth is caused by suppression of ERE-mediated transcription.

Although it is generally assumed that the zinc finger domains found in Egr family members affect transcription exclusively by interacting with their cognate DNA response element, recent studies have provided evidence that they may also influence transcription via direct protein-protein interactions with other transcription regulatory factors. For example, the zinc finger domain of Egr1, as well as full-length Egr1, has been shown to inhibit transcription mediated by $\mathrm{NF}-\kappa \mathrm{B}$, apparently via a direct interaction of the zinc finger domain with p65 RelA (Chapman and Perkins, 2000). However, it seems unlikely that inhibition of NF- $\kappa \mathrm{B}$ accounts for the ability of the Egr inhibitor construct to block neurite outgrowth, because this effect is not shared by full-length Egr1 (Y. Levkovitz, unpublished observations). Of note, we also found that overexpression of Egr1 does not trigger neurite outgrowth, indicating that Egr family member expression is necessary, but not sufficient, for eliciting neurite outgrowth.

Analysis of the signaling pathways linking NGF receptor activation to neurite outgrowth indicates that this phenotypic response is mediated via ras activation of the MEK-ERK cascade (Cowley et al., 1994; Segal and Greenberg, 1996). Because the MEK-ERK pathway plays a key role in regulating transcription via the SRE and the Egr1 promoter contains multiple SREs, we had assumed initially that Egr family induction by NGF would be downstream of MEK-ERK activation. However, because we found that the MEK inhibitor UO126 does not block the ability of NGF to activate the ERE reporter, we are forced to infer that there is a parallel, MEK-independent pathway linking NGF receptor activation to Egr family induction (Fig. 8C).

Because the ERE reporter assay we used in this study would be expected to respond to induction of either Egr1 or Egr4, it is conceivable that Egr1 induction is MEK dependent but that Egr4 induction via an MEK-independent pathway masks this blockade. However, this does not appear to be the case, because recent studies conducted in a variant of PC12 cells, referred to as PC12D, demonstrated that the NGF-induced rise in Egr1 mRNA is not inhibited by the MEK inhibitor PD098059, even at relatively high concentrations shown to block ERK activation completely in these cells (Kumahara et al., 1999). Furthermore, we have found in gel-shift studies conducted in PC12 cells that PD098059 does not suppress the ability of NGF to induce bands that correspond to either Egr1 or Egr4 (Levkovitz, unpublished observations). Thus, taken together, these studies indicate that there is an MEK-independent pathway linking NGF receptor activation to Egr family induction. This response to NGF could 
be mediated via MEK-independent pathways leading to the SRE (Kumahara et al., 1999; Hirabayashi and Saffen, 2000) or, conceivably, via other response elements.

As shown schematically (Fig. 8C), our findings indicate (1) that stimulation of MEK and induction of Egr family members by NGF are mediated by separate signaling pathways and (2) that both are required to trigger neurite outgrowth by NGF. Furthermore, the ability of constitutively active MEK to induce neurite outgrowth fits with this model, because (1) this construct activates the ERE reporter and (2) the Egr inhibitor construct blocks the ability of MEK to induce neurite outgrowth.

In summary, these results provide compelling evidence that the Egr family of transcription factors plays a central role in mediating the long-term effects of NGF. Because multiple members of this family are robustly induced in a wide variety of neuronal plasticity paradigms, our findings also suggest that the dominantnegative inhibitor strategy used in this in vitro preparation may also be useful for investigating the role of this transcription factor family in neuronal plasticity in vivo. Furthermore, this strategy should be helpful in defining the downstream targets of the Egr family in neurons.

\section{REFERENCES}

Abraham WC, Otani S (1991) Macromolecules and the maintenance of long-term potentiation. In: Kindling and synaptic plasticity, the legacy of Graham Goddard (Morrell F, ed), pp 92-109. Boston: Birkhauser.

Ahn S, Ginty DD, Linden DJ (1999) A late phase of cerebellar longterm depression requires activation of CaMKIV and CREB. Neuron 23:559-568.

Chapman NR, Perkins ND (2000) Inhibition of the RelA(p65) NF-kB subunit by Egr-1. J Biol Chem 275:4719-4725.

Chen C, Okayama H (1987) High-efficiency transformation of mammalian cells by plasmid DNA. Mol Cell Biol 7:2745-2752.

Christy B, Nathans D (1989a) DNA binding site of the growth factorinducible protein Zif268. Proc Natl Acad Sci USA 86:8737-8741.

Christy B, Nathans D (1989b) Functional serum response elements upstream of the growth factor-inducible gene zif268. Mol Cell Biol 9:4889-4895.

Cowley S, Paterson H, Kemp P, Marshall CJ (1994) Activation of MAP kinase kinase is necessary and sufficient for PC12 differentiation and for transformation of NIH 3T3 cells. Cell 77:841-852.

Crosby SD, Puetz JJ, Simburger KS, Fahrner TJ, Milbrandt J (1991) The early response gene NGFI-C encodes a zinc finger transcriptional activator and is a member of the GCGGGGGCG (GSG) elementbinding protein family. Mol Cell Biol 11:3835-3841.

Dash PK, Hochner B, Kandel ER (1990) Injection of the cAMPresponsive element into the nucleus of Aplysia sensory neurons blocks long-term facilitation. Nature 345:718-721.

Favata MF, Horiuchi K Y, Manos EJ, Daulerio AJ, Stradley DA, Feeser WS, Van Dyk DE, Pitts WJ, Earl RA, Hobbs F, Copeland RA, Magolda RL, Scherle PA, Trzaskos JM (1998) Identification of a novel inhibitor of mitogen-activated protein kinase kinase. J Biol Chem 273:18623-18632.

Frey U, Krug M, Reymann KG, Matthies H (1988) Anisomycin, an inhibitor of protein synthesis, blocks late phases of LTP phenomena in the hippocampal CA1 region in vitro. Brain Res 452:57-65.

Gashler A, Sukhatme VP (1995) Early growth response protein 1(Egr1): prototype of a zinc finger family of transcription factors. Prog Nucleic Acid Res Mol Biol 50:191-224

Gille H, Sharrocks AD, Shaw PE (1992) Phosphorylation of transcription factor $\mathrm{p} 62^{\mathrm{TCF}}$ by MAP kinase stimulates ternary complex formation at c-fos promoter. Nature 358:414-417.

Greene LA, Tischler AS (1976) Establishment of a noradrenergic clonal line of rat adrenal pheochromocytoma cells which respond to nerve growth factor. Proc Natl Acad Sci USA 73:2424-2428.

Gunning PW, Letourneau PC, Landreth GE, Shooter EM (1981a) The action of nerve growth factor and dibutyryl adenosine cyclic $3^{\prime}: 5^{\prime}$ monophosphate on rat pheochromocytoma reveals distinct stages in the mechanisms underlying neurite outgrowth. J Neurosci 1:1085-1095.

Gunning PW, Landreth GE, Bothwell MA, Shooter EM (1981b) Differential and synergistic actions of nerve growth factor and cyclic AMP in PC12 cells. J Cell Biol 89:240-245.

Guzowski JF, McGaugh JL (1997) Antisense oligodeoxynucleotide- mediated disruption of hippocampal cAMP response element binding protein levels impairs consolidation of memory for water maze training. Proc Natl Acad Sci USA 94:2693-2698.

Hirabayashi T, Saffen D (2000) M1 muscarinic acetylcholine receptors activate zif268 gene expression via small G-protein Rho-dependent and lambda-independent pathways in PC12D cells. Eur J Biochem 267:2525-2532

Johnson CM, Hill CS, Chawla S, Treisman R, Bading H (1997) Calcium controls gene expression via three distinct pathways that can function independently of the Ras/mitogen-activated protein kinases (ERKs) signaling cascade. J Neurosci 17:6189-6202.

Kim SJ, Park K, Rudkin BB, Dey BR, Sporn MB, Roberts AB (1994) Nerve growth factor induces transcription of transforming growth factor- $\beta 1$ through a specific promoter element in PC12 cells. J Biol Chem 269:3739-3744.

Kumahara E, Ebihara T, Saffen D (1999) Nerve growth factor induces zif268 gene expression via MAPK-dependent and -independent pathways in PC12D cells. J Biochem 125:541-553.

Lamprecht R, Hazvi S, Dudai Y (1997) cAMP response elementbinding protein in the amygdala is required for long- but not short-term conditioned taste aversion memory. J Neurosci 17:8443-8450.

Linden DL (1996) A protein synthesis-dependent late phase of cerebellar long term depression. Neuron 17:483-490.

Marais R, Wynne J, Treisman R (1993) The SRF accessory protein Elk-1 contains a growth factor-regulated transcriptional activation domain. Cell 73:381-393.

Milbrandt J (1987) A nerve growth factor-induced gene encodes a possible transcriptional regulatory factor. Science 238:797-799.

Montarolo P, Goelet GP, Castellucci VF, Morgan J, Kandel ER (1986) A critical period for macromolecular synthesis in long-term heterosynaptic facilitation in Aplysia. Science 234:1249-1254.

Nguyen PV, Abel T, Kandel ER (1994) Requirement of a critical period of transcription for induction of a late phase of LTP. Science 265:1104-1107.

O’Donovan KJ, Baraban JM (1999) Major Egr3 isoforms are generated via alternate translation start sites and differ in their abilities to activate transcription. Mol Cell Biol 19:4711-4718.

O'Donovan KJ, Tourtellotte WG, Milbrandt J, Baraban JM (1999) The EGR family of transcription-regulatory factors: progress at the interface of molecular and systems neuroscience. Trends Neurosci 22:167-173.

O’Donovan KJ, Levkovitz Y, Baraban JM (2000) Functional comparison of Egr3 transcription factor isoforms: identification of an activation domain in the $\mathrm{N}$-terminal segment absent from $\operatorname{Egr} 3 \beta$, a major isoform expressed in brain. J Neurochem 75:1352-1357.

Pang L, Sawada T, Decker SJ, Saltiel AR (1995) Inhibition of MAP kinase kinase blocks the differentiation of PC12 cells induced by nerve growth factor. J Biol Chem 270:13585-13588.

Price MA, Hill C, Treisman R (1996) Integration of growth factor signals at the c-fos serum response element. Philos Trans R Soc Lond [Biol] 351:551-559.

Qu Z, Wolfram LA, Svaren J, Ehrengruber MU, Davidson N, Milbrandt J (1998) The transcriptional corepressor NAB2 inhibits NGF-induced differentiation of PC12 cells. J Cell Biol 142:1075-1082.

Russo MW, Sevetson BR, Milbrandt J (1995) Identification of NAB1, a repressor of NGFI-A- and Krox20-mediated transcription. Proc Natl Acad Sci USA 92:6873-6877.

Segal RA, Greenberg ME (1996) Intracellular signaling pathways activated by neurotrophic factors. Annu Rev Neurosci 19:463-489.

Sevetson BR, Svaren J, Milbrandt J (2000) A novel activation function for NAB proteins in EGR-dependent transcription of the luteinizing hormone $\beta$ gene. J Biol Chem 275:9749-9757.

Sheng M, Greenberg ME (1990) The regulation and function of c-fos and other immediate early genes in the nervous system. Neuron 4:477-485.

Stanton PK, Sarvey JM (1984) Blockade of long-term potentiation in rat hippocampal CA1 region by inhibitors of protein synthesis. J Neurosci 4:3080-3088.

Sukhatme VP, Cao X, Chang LC, Tsai-Morris C, Stamenkovitch D, Ferreira PCP, Cohen DR, Edwards SA, Shows TB, Curran T, LeBeau MM, Adamson ED (1988) A zinc-finger gene coregulated with c-fos during growth and differentiation, and after cellular depolarization. Cell 53:37-43.

Svaren J, Sevetson BR, Apel ED, Zimonjic DB, Popescu NC, Milbrandt J (1996) NAB2, a corepressor of NGFI-A (Egr-1) and Krox 20, is induced by proliferative and differentiative stimuli. Mol Cell Biol 16:3545-3553.

Swirnoff AH, Milbrandt J (1995) DNA-binding specificity of NGFI-A and related zinc finger transcription factors. Mol Cell Biol 15:22752287. 